\title{
José Díaz y el Frente Popular
}

\section{VICTORIA FERNÁNDEZ LUCEÑO}

\section{INTRODUCCION}

Como es bien sabido, el Frente Popular fue el pacto que las fuerzas politico- sindicales obreras hicieron con las izquierdas republicanas, para presentar una candidatura conjunta a las elecciones del 16 de febrero del 1936 y quitarle a la derechas el poder que detentaban desde noviembre del 33, con actuaciones políticas y represiones de sobradas sospechas fascistas. Es el llamado Bienio Negro de la II República Española el provocador del Frente Popular Antifascista.

Se trata del entendimiento que se produce entre todos los antifascistas, después de la llegada de Hitler al poder, en enero de 1933.

Por eso, aunque el año de consolidación del frente popular fue el 35 , para estudiar la gestación del mismo, hay que remontarse al 33.

Estudiar el papel del PCE en la configuración del frente, es uno de los objetivos de esta comunicación. Y muy especialmente, partir de hacer una valoración de la labor de José Díaz Ramos, Secretario General del PCE, desde 1932. Aquí está lo novedoso del presente trabajo.

La figura de José Díaz ha sido minimizada quizás porque se arrancó siempre de la consideración de que fue un perfecto lacayo estalinista. Su nombre ha sido absorbido, imantado, por las siglas de su partido. No aparece, no es conocido, ni siquiera por los sevillanos no comprometidos con su círculo político. Rescatarlo para la Historia es una de las finalidades de este trabajo.

Una valoración histórica de aproximación, la ha hecho recientemente Rafael Cruz, en su libro sobre el comunismo en la II República española, donde dice que fue elevado a la Secretaría del partido porque en él . se unían la inteligencia, la fidelidad (a la política de la Internacional Comunista), y el prestigio.

Su verdadero labor empieza ahora, y en esta etapa nos centraremos, sobre todo a partir del año 33 en que, como ya hemos dicho, la lucha antifascista va a ser el objetivo prioritario del comunismo internacional. 
Estudiaremos el papel que desempeñó Díaz en esta toma de posición, su trabajo dentro del partido para conseguir el frente único obrero, primero por la base, después el bloque popular por el entendimiento entre los dirigentes sindicales y políticos de las distintas centrales y partidos. Así analizaremos el ingreso en las Alianzas Obreras en septiembre del 34, la fusión de las centrales en diciembre del 35, la coalición de enero del 36, el Frente Popular Antifascista.

Nos centraremos en la figura de Pepe Díaz, en el proceso de formación de dicho frente, y apoyaremos sus intervenciones públicas con información debidamente documentada.

No se conoce ningún análisis y comentario completo de sus discursos. De estos vamos a partir, preferentemente de los cinco que pronunció en un corto periodo que va del 2 de junio del 35 al 15 de febrero del 36 , o sea en la fecha de constitución del frente.

\section{LOS DISCURSOS DE JOSE DIAZ SOBRE EL FRENTE POPULAR}

Discursos pronunciados entre el 2 de junio del 35 y el 15 de febrero del 1936.

Son cinco discursos pronunciados en sucesivos mítines del Partido Comunista Español por su secretario, recopilados en el libro de José Díaz, Tres años de lucha,tomo I, de la página 7 a la 98 . El primero fue pronunciado en el Monumental Cinema de Madrid, el 2 de junio de 1935 y en él se condensa la labor histórica del Partido en España. El segundo, en el Coliseo Pardiñas, el 3 de noviembre de 1935. El tercero, en el Salón Guerrero de Madrid, el 9 de febrero de 1936. El cuarto y el quinto, en el Teatro de la Zarzuela de Madrid, los días 11 y 15 de febrero de 1936.

\section{LA LUCHA POR LA UNIDAD EN PLENA ACCION. DISC JRSO PRONUNCIADO EN EL MONUMENTAL CINEMA, MADRID, 2 DE JUNIO DE 1935}

A través de este discurso vamos a conocer el papel histórico del PCE y de su secretario en la España republicana.

Habla José Díaz, Secretario General del PCE desde otoño del 32. Se dirige a obreros socialistas y anarquistas con la finalidad de organizar la lucha de masas. El auditorio está abarrotado por diez mil obreros en el Monumental y además hay millares en la calle, después de diez meses de ilegalidad del PCE. Hace un planteamiento de la gravedad de la situación que se vive en España por las actuaciones fascistas del gobierno. Renueva el llamamiento de los comunistas a los obreros, a los campesinos, a los hombres libres, a los antifascistas, a los republicanos de izquierda, 
para formar el Bloque Popular Antifascista y pasa a relatar, las actuaciones del PCE antes de la Revolución de Octubre. Parte del principio de que el PCE ha luchado siempre por la iunificación de las fuerzas obreras", y lo hizo a través de las siguientes actuaciones:

I.- Resolución del Pleno Extraordinario del Comité Central del PCE ( Sección de la I. C.)), celebrado en septiembre de 1934, de . Organizar el Frente Unico de lucha, en forma permanente y con carácter nacional, para dar la batalla a la contrarrevolución: ¡ Tal es el anhelo de las masas trabajadoras!:

Analizamos dicha Resolución, fechada el 13 de septiembre del 34 porque es el documento base de su discurso, la que marcó la línea de actuación del Partido en el año transcurrido (de septiembre del 34 a junio del 35)'.

En dicha resolución se plantea una dicotomía de la situación española en un período en que se van a librar combates decisivos entre BARBARIE, ESCLAVITUD, HAMBRE Y TERROR por el lado contrarrevolucionario; TIERRA, PAN Y LIBERTAD, si triunfa la revolución de los obreros y campesinos. Y desarrolla seis puntos:

1) Que la burguesía y los terratenientes tienen en España un fascismo disimulado con el manto de - democraciav.

2) Que los obreros y campesinos y las masas y nacionalidades oprimidas responden con contragolpes duros pero no tienen organizadas las fuerzas revolucionarias.

3) Que hay un gran entusiasmo en las masas por el frente único y que se tiene que organizar con carácter nacional y en forma permanente.

4) Que la manera de organizar la revolución es a través del Gobierno Obrero y Campesino, de los Comités de Fábricas y de campesinos, embriones de los Soviets.

5) Ahora bien, ^los camaradas socialistas, basándose en una sédicente característica de la revolución española, plantean el problema de las Alianzas Obreras como reemplazantes de los Soviets. Pero no pueden reemplazar a los soviets si las Alianzas no se llaman también campesinas, y no solamente cambian de nombre sino de contenido, incorporando en sus filas a la organización del campesinado. Además tienen que estar en ellas, la CNT, la CGTU, los Sindicatos Autónomos, los obreros "inorganizados", los "parados" y los trabajadores en uniforme. Que las Alianzas se rijan por las reglas de la democracia proletaria y que los representantes en ellas sean designados democráticamente por asam-

(1) Resolución del Pleno Extraordinario del Comité Central del Partido Comunista de España ( Sección Española de la Internacional Comunista) sobre la participación en las Alianzas Obreras. ARCH. PCE/FIM. sección Documentos. Microfilmado. 
bleas de los trabajadores de los organismos que las integran. Que sean órganos de Frente Unico y que se basen en los Comités de Fábricas y de Campesinos y tiendan a la creación de los soviets.

6) Se pronuncia por el ingreso de todas las organizaciones en el seno de las Alianzas, allí donde existan, e invita a que se creen allí donde todavía no existen. El fín es conseguir una sóla central sindical de lucha de clase para hacer posible el Frente Unico y el triunfo de la revolución. Manteniéndose en el terreno firme del marxismo-leninismo ${ }^{2}$.

El autor de este texto es un delegado de la internacional y por su estilo podríamos apuntar a Victor Codovilla, dirigente comunista argentino de origen italiano, que actuó en Ėspaña desde principios de los años $30^{3}$. Fue el promotor de José Díaz al Secretariado y el año de su muerte escribe un libro sobre él, del que extraemos la semblanza que hace de Pepe en estos significativos párrafos ${ }^{4}$ :

- Los rasgos sobresalientes de José Díaz, de ese obrero sevillano educado en el Partido de los comunistas, son los de un jefe obrero y popular de extraordinaria inteligencia, de gran sensibilidad política, con sólidos conocimientos teóricos adquiridos por el estudio y en el fragor del combate, dotado de un espíritu práctico y realizador, de una capacidad de organización demostrada en todos los terrenos: económico, político, social y militar; todo lo cual unido a una modestia innata y a un hondo sentimiento de compañerismo, determinaba en cuantos tuvieron la suerte de conocerle, admiración y cariño personal, y respeto y adhesión a la causa por él mantenida...unía a la firmeza de principios, la flexibilidad en la táctica; al

(2) Para la formación de las Alianzas Obreras se puede consultar el artículo de Marta Bizcarrondo, en la revista de Estudios de $H^{a}$ Social, Madrid, 1981.

(3) Paolo Spriano, en la introducción a los Escritos sobre la guerra de Palmiro Togliatti, dice que Victor Codovilla. actuó casi como tutor. del partido a principios de los años treinta, y es el primero de su lista de delegados rusos en España.

(4) Victor Codovilla. José Díaz, Editado dos veces en el año 1942 que como sabemos es el de su muerte en Tbilisi. Ed.Anteo,Buenos Aires.

En el Acta del Buró del Partido, reunido el 5, 6 de octubre del 32 que puede consultarse en el ARHC.PCE/FIM. Sección Documentos.Vol.13, film V ( 14 pág.) se pueden leer las intervenciones de destacados dirigentes comunistas. Codovilla utiliza el seudónimo de Medina y hace afirmaciones para acusar al grupo dirigente anterior (Bullejos, Adame, Vega) de - aislar la delegación de la base del partido., y - en lo sucesivo dice que es menester que exista una dirección homogénea y una justa comprehensión de la política de la IC., y que - en ningún momento la IC ha impedido a los Partidos la discusión de sus decisiones ya que nadie es infalible. y clasifica de sectaria la posición que adoptan muchos camaradas al decir que no tenemos camaradas capacitados para cumplir las tareas de la dirección del Partido demostrando lo contrario. En su intervención, Pepe declara firmemente que sin vacilaciones de ninguna clase está dispuesto a defender la línea política. de la IC. y vuelve a insistir en que no se considera suficientemente preparado para desarrollar el trabajo que tiene encomendado. 
entusiasmo revolucionario el realismo para determinar el momento de la acción; al espíritu de sacrificio y de abnegación la voluntad de luchar y de vencer en el combate a las fuerzas de la regresión y de la barbarie fascista, de hacer triunfar a las fuerzas de la civiliza ción y del progreso. Así pues; la I.C. de Moscú, a través de sus delegados, como se desprende del texto de la resolución, renunció a los soviets y a la bolchevización de la lucha obrera en general y se adaptó a la manera españolas. Cabe pensar que fue el gran prestigio de Pepe Díaz y de su Secretariado el que logró convencer a la delegaçión de Moscú de que en España todo era diferente, después de varios años de pretender lo contrario.

El Frente Unico en España se obtendría con el reconocimiento de que el partido de masas en España era el PSOE y su central sindical, la UGT, y había que asumir el tipo de unidad que estaban dispuestos ambos a ir asimilando con los comunistas, las Alianzas Obreras.

En un primer momento, la búsqueda de posicionamiento del PCE se hace a través de los Comités de Reconstrucción de la lucha obrera de otros sindicatos ${ }^{6}$. Pepe Díaz, procedente del anarquismo sevillano sería una pieza clave en dichas actuaciones ${ }^{7}$. En el verano del año 31 hay un viraje que afecta a la organización del Partido y su relación con el sindicato. Se pasa del sindicato de reconstrucción al de unidad sindical. Así nace la CGTU;

El segundo cambio es el que estamos analizando, cuando la IC da permiso a la central sindical del PCE, la CGTU, para que entre en las

(5) En Noticias bistóricas de la guerra de España, F.Largo Caballero da la información de que a través de Margarita Nelken se entrevistó, en la sede de la UGT, con un representante de la III Internacional, llamado Medina, girando toda la conversación sobre si Alianzas Obreras o Soviets, negándose a los soviets porque esta terminología no se adaptaba a las costumbres de España. Ed.Pablo Iglesias, 1985, pg. 142.

(6) La U.L.S. de Sevilla llegó a tener el control total se sectores del sindicalismo sevillano como del puerto gracias a Saturnino Barneto, de los panaderos, con Pepe Díaz y Antonio Mije, etc... Su secretario general fue Carlos Nuñez. J.M.Macarro: La utopía revolucionaria. Sevilla en la Segunda República. Publicado por Monte de Piedad y Caja de Aborros de Sevilla, en 1985.

La prensa sevillana de esa década contiene sustanciósos datos de las actividades obreras. Especialmente importante es el apartado de .Vida Societaria., pequeño recuadro de -El Liberal. de Sevilla que proporciona mucha y puntual información sobre reuniones y actividades diversas de los gremios en dichos años, incluso con la censura de la época de las dictaduras. La biografía en preparación de José Díaz Ramós aportará datos sobre el tema.

- (7) Consultar José Díaz Ramos (aprocimación a la vida de un lucbador obrero) de $M^{a}$ Victória Fernández Luceño, editado por el Servicio de Publicaciones de la Universidad de Sevilla, en Sevilla, el año 1992. Contiene un extenso apartado dedicado a la primera escuela de lucha de Pepe Díaz, p. 39 a 72.

(8) Resolución del CE sobre la huelga de Sevilla. ARCH PCE/FMI. Sección Documentos. FILM IV. 16 de julio del 31. 
Alianzas Obreras Socialistas, poniendo sus condiciones, como hemos relatado ya en la descripción del contenido de la resolución. Puede afirmarse, sin miedo a equivocación alguna, que la labor del Secretariado en la época de José Díaz, supo mantener la concordia de los comunistas españoles entre sí y todos con la delegación de la IC, la cual debió valorar a través de sus delegados muy positivamente su actuación al frente de la Secretaría General, al contrario que en la etapa anterior donde los conflictos internos fueron de todo tipo, terminando con el proceso y la expulsión de Bullejos, Adame, Vega y Trilla?.

II.- Ingreso del PCE en las Alianzas Obreras para convertirlas en Frente Unico. Atribuye el éxito revolucionario de octubre, en Asturias, a que las Alianzas Obreras estaban allí muy organizadas en Comités de Frente Unico, y el fracaso revolucionario, en el caso contrario.

El 18 de septiembre de 1934, el CC del PCE ( Sección de la IC), envía a todos los Comités Provinciales y Regionales del Partido, la Resolución del CC Extraordinario, calificándola de trascendental importancia para el desarrollo rápido del Partido, por tanto ha de ser conocida desde los Comités Provinciales hasta el último militante de la célula ${ }^{10}$. *... nuestras organizaciones deben tomar las medidas prácticas para llevar a cabo las decisiones en lo que se refiere a nuestro ingreso en las Alianzas Obreras provinciales y locales, a constituirlas en donde aún no existen, como así mismo en lo que se refiere a la realización práctica de la Unidad Sindical...*

El mảndato era que en el curso de diez días los Comités Provinciales enviasen un informe al Comité Central sobre la discusión realizada y sobre los resultados obtenidos en el trabajo práctico sobre dicho mandato. A lo largo de los meses siguientes, se fueron constituyendo. Así lo hizo el Comité Provincial de la Alianza Obrera y Campesina de Toledo, el 26 de enero del 35, firmando dicha acta el representante del Secretariado Provincial de la Tierra, UGT; el representante Provincial de la CGTU; el Secretario General de la Federación Provincial Comunista; y el Secretario General de la Federación Provincial de Juventudes Comunistas. Este organismo tenía como finalidad la lucha contra el fascismo, la amnistía, la apertura de los centros obreros, que todos los sindicatos de la provincia llegasen a la unidad sindical, una sóla central y un sólo partido de clases. Sus reivindicaciones serían la abolición de la pena de muerte, la igualdad

(9) Acta de la reunión del BP del Partido, 5-6 de octubre citada. Consultar Rafael Cruz. El Partido Comunista de España en la II República. Alianza Universidad, Madrid, 1987. Trata extensamente el problema y está muy bien documentado pero sus referencias al archivo del PCE de Madrid son confusas porque no responden a la ordenación del mismo.

(10) ARCH PCE/FIM. Microfilmado. 
de derechos para las mujeres y para los jóvenes obreros; • a igual trabajo igual salario. Y se proyectó la reunión de un Congreso Provincial ${ }^{11}$.

La misma fórmula de constitución se utiliza para la A O C de Málaga, el 27 de febrero del 35, en donde firman también por el Partido Comunista y por el Socialista ${ }^{12}$. Puede consultarse el documento, fechado de marzo a junio del 35 , con la relación de todas las A O C constituidas en dicha fecha en toda España. Por los textos cotejados, podemos concluir, que el argumento del discurso de que la revolución de octubre del 34 pudo hacerse en aquellos lugares donde estaban constituidas ya las alianzas, puede invertirse. Es la revolución de octubre del 34 y la represión del gobierno que siguió a ella, la que desarrolló la unión que describimos, ya que fue el comienzo del año 35 el de constitución de las Alianzas Obreras.

III.- Posición del PCE en el movimiento de Octubre: Comunistas, Socialistas y Anarquistas lucharon confundidos, thombro a hombro: y por eso triunfaron en Asturias. José Díaz recaba para el PCE toda la responsabilidad política que se derive del movimiento de la insurrección victoriosa de Asturias, la 'Gloriosa Comuna. Así pues, convierte a la revolución de Asturias en bandera de la lucha antifascista, a los comunistas en sus protagonistas, a sus represaliados, en víctimas y héroes. Arremete contra el gobierno al que llama : del hambre, de la sangre y de la muerte y ataca duramente a la CEDA, diciendo que la misión de los católicos de la CEDA consiste en enviar a los moros a "pacificar" a los * cristianos" con las gumias y a los degenerados del tercio a imponer el • orden. en Asturias. Planteada así la situación, el PCE se dirige a todos los antifascistas para organizar la lucha en frente único contra la represión y contra la pena de muerte, como ya lo hicieran por el indulto a los veinte condenados por el gobierno represivo, y dice: "esta lucha en frente único y en frente popular, antifascista que consigue los veinte indultos, es la primera gran batalla ganada al enemigo por el proletariado después de Octubre. La fuerza está en que, ' en cada trabajador, en cada antifascista, en cada persona honrada hay un revolucionario", por tanto Gil Robles y sus amos tendrían que matar a todos los que con su trabajo les dan de comer. Previene del peligro que supone tener a Gil Robles de ministro de guerra y hace una llamada a la comprensión de ésto a todos los socialistas, a todos los anarquistas y a todos los republicanos de izquierda.

La última parte del discurso la dedica a mostrar la manera cómo lograr que triunfe en España la revolución, y sus argumentos, dos meses antes del VII Congreso de la IC, se basan en la preparación de éste por. el PCE desde principios del año 35. La Resolución del Buró Político del

(11) ARCH.PCE/FIM. Sección documentos. Microfilmado.

(12) ARCH PCE/FIM. Microfilmado. 
$\mathrm{PCE}^{13}$ contiene dieciocho puntos que son otros tantos interrogantes sobre la situación del Partido y los planteamientos que habría que hacer para que el éxito del Partido se correspondiera con el espíritu revolucionario que había en la España del momento. Una de sus interrogantes, la $\mathrm{n}^{\mathrm{Q}} 11$, es sobre cuáles son los partidos fascistas españoles y cómo se puede llegar a la creación de una amplia concentración antifascista.

1.- Formación del Bloque Popular, alrededor de la A O C pero incluyendo a otros, a los empleados y funcionarios, a los intelectuales honrados, a los artesanos, a los pequeños industriales y comerciantes y a todos los que aborrecen el fascismo. Esta formación debe estar dirigida por el proletariado y a su cabeza el Partido Comunista y su Internacional que cuentan con un país en donde ha triunfado la revolución, la URSS. Las fuerzas que han de unirse son además del PCE, el Partido Socialista, las Juventudes Comunistas y Socialistas, los anarquistas, los sindicalistas y los republicanos de izquierda. Y ha de hacerse con reuniones a nivel nacional, provincial y local de sus representantes. Se duele de que siendo todos antifascistas, se estén celebrando por las mismas fechas tres mítines distintos, ( en el Monumental, en el Pardiñas y en el Europa), en lugar de uno sólo que era lo que los comunistas habían querido. A este bloque es al que llama Concentración Popular Antifascista, entendido aquí como unidad de lucha, del Frente Unico de los Obreros ampliado a todos los antifascistas.

2.- Apoyo al pacto franco soviético que es la línea de Lenin, dice, seguida por Stalin, como * coincidencia momentánea., ante el peligro de guerra del fascismo alemán. :Momentáneamente existe una coincidencia ocasional entre Francia y la URSS que les ha hecho firmar el pacto para detener los propósitos guerreros del fascismo alemán ${ }^{14}$.

3.- Programa minimo de lucha antifascista, de obligatorio cumplimiento para los que entren en la Concentración Popular Antifascista. En virtud de cuatro puntos que son :

:12. Confiscación de la tierra de los grandes terratenientes, de la Iglesia y de los conventos, sin ninguna indemnización para entregarla inmediata y gratuitamente a los campesinos pobres y a los obreros agrícolas*. $\times 2^{2}$. Liberación de los pueblos oprimidos por el imperialismo español. Que se conceda el derecho de regir libremente sus destinos a Cataluña, a Euskadi, a. Galicia y a cuantas nacionalidades estén oprimidas por el imperialismo de España. $.3^{\circ}$. Mejoramiento general de las condiciones de vida y de trabajode la clase obrera (aumento de salarios, respeto de los contratos de trabajo, reconocimiento de los sindicatos de lucha de clases, amplia

(13) ARCHPCE/FIM.Microfilm. Bandera Roja, $n^{2}$ 8.Febrero de 1935.

(14) Primer ejemplar de Este Rojo. Año 35. Art. El Pacto Germano Soviético, p. 8 y Francia marca el camino, p.3. Thorez. “onsignas lanzadas y realizadas por el PCF. ARCH.PCE/FIM. Sección documentos. Microfilmado. Las palabras en negrilla figuran como en el original. 
libertad de opinión, de reunión, manifestación y prensa para los obreros, etc... etc...)r..4ํ. Libertad para todos los presos revolucionarios. Amnistía total para los presos y perseguidos de carácter políticosocial.

4.- Medios de acción: Por último marca los requisitos imprescindibles para lograr el triunfo del Bloque Popular:

Que se convoquen nuevas elecciones en las que hay que conseguir el triunfo gracias a la unidad de todos los antifascistas.

-Que se forme un Gobierno revolucionario provisional que de satisfacción a los obreros y a todas las masas populares, a todos los antifascistas; que se comprometa ante las masas a realizar el programa de la Concentración Popülar Antifascista.

Que se le exija por parte del pueblo revolucionario que cumpla sus compromisos y que si no lo hace, se le eche. Esta última parte del discurso de José Díaz contiene la aportación que el PCE hizo a las actuaciones a seguir por el Frente Popular español del 36. De todos es conocido que el pacto que firmaron las izquierdas republicanas con los socialistas, comunistas y sindicalistas en nada se parece a los textos confeccionados por socialistas y comunistas, ni al propio de cada uno ni al que redactaron conjuntamente ${ }^{15}$.

La valoración del éxito de este mitin fue hecha por el Comité Provincial de Madrid; en el Boletín Semanal, $\mathrm{n}^{\circ} 71$, publicado en la primera semana de junio del 35. La consecuencia inmediata sería el reclutamiento para el Partido de 166 militantes. Se aprovechó la popularidad alcanzada para hacer una ofensiva de propaganda sobre Madrid en el mes de junio, antes de la celebración del Congreso Provincial ${ }^{16}$.

\section{EL VII CONGRESO DE LA IC SEÑALA EL CAMINO. DISCURSO PRONUNCIADO EN EL COLISEO PARDIÑAS, EL 3 DE NOVIEMBRE DE 1935}

Han pasado sólo cinco meses desde que pronunció, en el mitin de Madrid, en el Monumental, su discurso sobre la Concentración Popular Antifascista y el proceso de formación de la unidad de las izquierdas en España ha madurado notablemente. El propio orador lo describe en la primera parte de su discurso que pronunció a la vuelta de Moscú, después

(15) Santos Juliá: Origenes del Frente Popular en España (1934-36). Siglo XXI editores, Madrid, 1979. En las páginas 216 a 223 incluye el texto completo del Manifiesto electoral de Izquierdas.

Francisco Largo Caballero en Escritos de la Repuiblica, editorial Pablo Iglesias, con edición, estudio preliminar y notas de Santos Juliá, Madrid, 1985, contiene los documentos intercambiados entre los partidos y entre las distintas sensibilidades dentro del Partido Socialista Obrero Español.

(16) ARCH.PCE/FIM. Sección Documentos. Microfilmado. 
de la celebración del VII Congreso de la IC, entre el 25 de julio y el 20 de agosto. El Secretario general del PCE había ido con la representación de la delegación española. Le habían acompañado cinco obreros socialistas y cinco comunistas y habían expuesto los hechos revolucionarios de Octubre del 34 en Asturias. Fue el Congreso llamado por Díaz de todos los antifascistas. Pero, el discurso fue pronunciado al día siguiente de que apareciera en el diario socialista caballerista .Claridad. una nota en contestación a la carta del Comité Central del PCE de formar el frente único entre los socialistas y los comunistas. José Díaz lee la nota al comienzo del discurso y la califica de significativa pára el paso definitivo a la unidad -orgánica", o sea hacia la formación de un sólo partido socialista. Además, la cita textual pide, al final, que se diriman las diferencias de criterio, * en aras de la unidad política y sindical del proletariado revolucionario, nuestra aspiración más clara. O sea, unidad de los partidos y fusión de los sindicatos. Se manifiesta como portavoz de la VII Internacional, y pasa a explicar su mensaje. Se apoya para su disertación en citas textuales de la prensa (como .Claridad. y el .Debate.); en libros como El Extremismo, enfermedad infantil del Comunismo de Lenin, y Frente Popular en todo el mundo de Dimitrov, el gran protagonista del Congreso.

"A una nueva situación mundial corresponde nueva táctican:

A. El Socialismo ha vencido claramente al capitalismo en la sexta parte del mundo y pasa a citar los avances en la URSS.

B.•El fascismo alemán subió al poder por la división de las fuerzas proletarias", concluyendo que es una experiencia que hay que utilizar en el planteamiento de lucha antifascista.

C. El Frente Popular contra el fascismo a partir del Frente Unico proletario es imprescindible pero también hay que buscar aliados no proletarios", en la lucha a muerte contra el fascismo.

D. El ejemplo francés del Frente Unico realizado por los comunistas y los socialistas, ha movilizado a inmensas masas populares y alejado el peligro del fascismo en Francia.

E. La simpatía que despierta ahora en todo el mundo el comunismo, por el desarrollo de la URSS y de muchos partidos comunistas, y su atractivo para la pequeña burguesía, son enteramente nuevos.

F. La existencia real de fascismos en cierto número de paises.

G. La visión clara que la III Internacional, VII Congreso, ha tenido de la situación del momento, a las puertas de la más espantosa de las guerras; existen ya tres frentes. Predice, con gran acierto, que al fascismo italiano sucederá el alemín en el ataque imperialista. Por eso hace un llamamiento contra el fascismo y la guerra.

A continuación, analiza la situación española. Ya tiene respuesta a la cuestión 11 de la resolución del Buró de febrero del 35, sobre el fascis- 
mo. No hay un gobierno fascista todavía, pero sí muchos ministros que lo son (el de Guerra, Gil Robles) y comportamientos corruptos del Gobierno (estraperlo: Salazar Alonso), y clama porque llegue el día en que el Tribunal del Pueblo los juzque.

Medidas de aplicación en el cambio de táctica son:

1. Es necesaria la acción y el empuje de las masas trabajadoras y antifascistas para hacer morir al Gobierno. Se deduce de esta táctica de acción la disolución de las Cortes y la convocatoria de elecciones generales anticipadas, del discurso anterior.

2. Acudir a esas elecciones como Frente Unico a través de la A O C, ya que El frente único inspiraría a las capas vacilantes la fe en la fuerza de la clase obrera.(Dimitrov).

3. Unidad Sindical, una sola central.

4. Frente Popular Antifascista sobre la base del Frente Unico proletario. de Dimitrov, atrayendo a la pequeña burguesía explotada también por el capitalismo.

5. El Bloque Popular que lleve al Poder Obrero y Campesino. 6. Cita las reivindicaciones (tierra, paz, pan y libertad) de la unidad del bloque, del discurso del Monumental, menos el punto tercero, de las naciones oprimidas. Por último, resume el objetivo inmediato que es Democracia contra Fascismo. Confía en el Partido socialista y en su camarada dirigente, Largo Caballero que - llevará al partido socialista por la ruta del Frente Unico con los comunistas. Es la táctica de entendimiento con las fuerzas socialistas políticas y sindicales que alarmaría a Azaña, sobre todo cuando la CGTU entró en la UGT, en diciembre, como mandaba la consigna internacional en los casas de sindicatos de escasa implantación.

\section{LA ESPAÑA REVOLUCIONARIA. DISCURSO PRONUNCIADO EL 9 DE FEBRERO EN EL SALÓN GUE"?.?ERO DE MADRID}

Entre el anterior discurso er. Jardiñas y éste han pasado tres meses decisivos en la evolución histórica del proceso electoral español. Se ha hecho realidad el pacto del Frente Popular que fue firmado el 15 de enero anterior. Por tanto, no es de extrañar que el discurso de Díaz comience con aires mitineros, electoralistas y triunfalistas porque es evidente que el PCE desempeñó un papel importante, decisivo, en la formación de la candidatura ${ }^{17}$. El Bloque Popular está ya constituido, es su primera idea a destacar; lo que hay que hacer es que : cumpla su misión el 16 de febrero y después de esa fecha. O sea para José Díaz es de naturaleza orgánica

(17) Santos Juliá: Manuel Azaña. Una biografía politica. Alianża Editorial,Madrid, 1990.10,p.447, la ziltima coyuntura. 
como quiso antes el Frente Unico obrero. Su segunda idea interesante es el análisis que hace del significado de las elecciones que para él son importantísimas porque con ellas el pueblo español se juega la solución al dilema planteado en el discurso del Monumental. Es la resolución de la lucha entre las fuerzas del pasado y las del porvenir, entre los verdaderos * patriotas", a los que como novedad suma los republicanos históricos y mártires; y la España Inquisitorial, representada en los Calvo Sotelo, Gil Robles y Primo de Rivera.

A su pregunta de "QQué queremos hacer de España?", se contesta que lo contrario de lo que han hecho los que hasta ahora han dirigido, que llevaron a la juventud a la guerra de Marruecos, dieron la riqueza de España al capital extranjero, sumieron a los obreros y campesinos en el analfabetismo y la cultura en el oscurantismo de curas y frailes. En su discurso se acerca a los problemas de la mayoría de los españoles (del $90 \%$ dice, oprimidos por una minoría) que sufren el hambre, la cárcel, la incultura y una tremenda desigualdad en el trato de sus derechos como personas y contrapone esta situación a la de la URSS, con citas de Lenin.

Se marca "El camino para triunfar" que es: Expropiar la tierra sin indemnización y que el campesinado sea su dueño. Libertad religiosa pero que cada uno pague sus creencias. Un ejército del pueblo y respeto a las nacionalidades históricas (Cataluña, Euskadi y Galicia) para que sean libres. Estas que no habían sido citadas en el discurso de Pardiñas, vuelven a estar en su programa. Libertades democráticas plenas: de reunión, de manifestación...Que desaparezcan las organizaciones fascistas. El Bloque Popular hay que mantenerlo después de las elecciones, con su programa mínimo que el CC del PCE hará cumplir, así como el programa de la revolución democrático- burguesa hasta llegar al fin.

Termina pidiendo un sólo Partido marxista- leninista para lo que confía en Largo Caballero, la dictadura del proletariado y la España Socialista. Para arrancar los presos de las cárceles, pide a las mujeres y a los anarquistas que voten.

\section{LOS OBREROS UNIDOS.DISCURSO PRONUNCIADO EN EL TEATRO DE LA ZARZUELA, DE MADRID, EL 11 DE FEBRERO DE 1936}

Este discurso fue organizado por los Sindicatos de Artes Blancas y va dirigido a los sindicalistas y es más radical. Ya desde el principio marca el objetivo fundamental: conseguir el Frente Unico y la unidad de acción. Unificados los sindicatos socialistas en la UGT, hay que llegar ahora a unir los Partidos. Los sindicatos no pueden desligarse de la lucha política ya que ellos se inspiran en la lucha de clases. Los sindicatos de la Cr !T tienen que votar al Bloque $P$ ular, comc han dicho van a hacer loz ce Gijón ya que quien se abstien vorece a la reacción. Pone en duda la parcialidad 
prometida por el gobierno ya que en todas las provincias hay quejas de que los que trabajan para el Bloque Popular tienen dificultades. Se afirma en la seguridad del triunfo y niega el de los fascistas, porque le: provocan con sus armas lo cual es símbolo de debilidad y en que el proletariado tiene que hacer la revolución democrático-burguesa para la que la burguesía no está preparada. Compara a España con Rusia entre la revolución de febrero y la de octubre del 17, y propone empezar por ejecutar el programa mínimo para después continuar y arrollar a quien se interponga en su camino. Primero el P. cumplirá con el Bloque Popular pero al mismo tiempo habrá de realizar el programa del Gobierno Obrero y Campesino, antesala de lo que vendrá después, la dictadura del proletariado y el mismo régimen que la URSS. El proceso no será largo si se unifican los dos partidos socialistas.El medio es la unidad sindical como la fusión de la CGTU con la UGT ya realizada, así también deben hacer los Sindicatos autónomos ( cita el ejemplo de Sevilla, con nueve mil afiliados).

Todos los trabajadores que no están sindicados deben hacerlo a la UGT. También los de la CNT porque, según él, no había tantas diferencias entre los que pertenecían a una misma clase.

Se afirma en que las AOC son necesarias para llegar al FUP.

Programa la lucha electoral como una puesta en pie de acción de todo el proletariado como una muralla inexpugnable. Propone adoptar todas las medidas de organización y tomar las calles. Dirigiéndose a la CNT, le pide que voten al Bloque Popular que • por ello no dejareís de ser anarquistas sino que habreís cumplido con vuestro deber como revolucionarios. Se congratula de que cada vez vayan más mujeres a los mítines.

Por último, pide la votación a la candidatura íntegra. Que a ningún comunista se le ocurra borrar ningún nombre de la candidatura. Expresa su confianza en la disciplina de voto de los comunistas y desea que los demás también la tengan, porque tachar un nombre es contribuir a la victoria de la reacción y a que haya un bandido más en el Parlamento.

\section{EL BLOQUE POPULAR, INVE ¿IBLE E INDESTRUCTIBLE. DISCURSO PRONUNCIADO EN EL TEATRO DE LA ZARZUELA DE MADRID, EL 15 DE FEBRERO DE 1936.}

Dirigido al pueblo de Madrid, a los obreros y antifascistas de toda España, su contenido es menos ideológico y más táctico porque se trata del breve discurso que pronuncia la víspera de la votación ${ }^{18}$. Por fin es su mitin deseado desde junio del 35, porque actúan juntos comunistas, republicanos de izquierda (Martinez Barrio y Azaña) y socialistas ( Largo Caballero).

La ideas principales que contiene son: El gobierno no es imparcial ya que en todos los pueblos de Españn hay quejas de que los propagandistas del Bloque Popular tienen problemas en la campaña. Los monárquicos 
tienen miedo y preparan un golpe de Estado, si triunfa el Bloque Popular. Insiste, de nuevo, en que los comunistas están dispuestos a defender lo que salga de las urnas, mantener la unión antifascista y exigir la disolución de las ligas antifascistas.

Termina el discurso con unas palabras de Saint- Just: "Vuestro interés manda no dividiros, cualesquiera que sean las diferencias de opinión. Nuestros tiranos no admiten esas diferencias entre nosotros. Os venceremos todos o desapareceremos todos". Y apostilla, hay que hacer lo que la Revolución francesa de 1789 . destruir los residuos del feudalismo que son una de las bases materiales de la reacción.

Recurrir a textos revolucionarios burgueses es un emblema de a lo que estaba dispuesto a transigir el PCE y la IC porque España fuera el muro de contención del Fascismo.

\section{CONCLUSIONES}

Hemos querido destacar el papel de José Díaz a través de sus discursos- mítines electorales de las elecciones del 36 y hemos llegado a dos conclusiones fundamentales:

1. Afirmación de la personalidad de José Díaz como figura clave en el desarrollo politico del PCE. Su promoción por Victorio Codovilla (Medina) al que no defraudaría en su confianza.Su trabajo serio, conciliador pero firme en dos determinaciones:

a) Su fidelidad a la "casa" ( la IC), ya que tuvo fe en la URSS y en su Internacional y seguridad de que sacaría a la clase obrera de la total postración en que estaba España. Después de militar diez años en el anarquismo, se asienta en el posibilismo revolucionario, siempre como activista.

b) Actitud de trabajo y lucha que da como fruto el progreso y desarrollo del Partido en sus años de Eecretario General.

2. Valoración del papel del PCE en la formación del Frente Popular.

Desde 1934, el PCE es el crear'or de la política de unidad. Primero de los obreros entre sí, Frente Unico Proletario, con la unión de los sindicatos, de los partidos y de las juventudes obreras; después, desde junio del 35, de todos los sectores interclasistas antifascistas, Concentración Popular Antifascista, Bloque Popular o Frente Popular. Fue el PCF el preconizador de dicha política de Frente Popular y el PCE con José Díaz, el que precipitó los acontecimientos para poder celebrar elecciones, que llevaran a su triunfo en España. No era su programa pero sí su proyecto inmediato, de ahí que la actitud de respeto y apoyo al gobierno que salió de las urnas, el 16 de febrero del 36 , fuera el resultado de lo que exponemos.

(18) El Sol, Madrid, 16 de febrero: ...* el local es.uvo rebosante de público y los discursos fueron tansmitidos a siete teatros de Madrid y a numerosas poblaciones de España. 